\title{
Service quality expectation and cultural diversity in fast fashion retailing
}

\begin{abstract}
Fast Fashion the production highly fashionable and affordable items under uncertain demand and short lead time, has become a global industrial trend in recent decade. With the increasing popularity, competition among fast fashion retailers has been focused on improving design, price and service quality in order to differentiate themselves from their competitors. Understanding and improving service quality, which has a direct interaction with customers, is crucial especially in cities with a blend of different cultures. This study draws attention on how cultural values are affecting customers' service quality expectations in Hong Kong fast fashion retailing. This study considered 283 cultural-diversified respondents with previous shopping experience in Hong Kong fast fashion stores. With a service quality measurement tool specified for Hong Kong fast fashion retailing situation, this study confirmed the significance of cultural perspectives in shaping customers' service quality.
\end{abstract}

Keywords: cultural diversity, global fashion industry, intangibility, heterogeneity, perishability, inseparability, reliability, retail service quality scale, masculinity, crosscultural researches, filtering question, service quality expectation, cultural dimensions, fast fashion retail, strongly disagree, fashionable design
Volume I Issue 3 - 2017

\author{
Ameersing Luximon, Pui Ying Chan \\ Institute of Textiles and Clothing, The Hong Kong Polytechnic \\ University, Hong Kong
}
Correspondence: Ameersing Luximon, Institute of Textiles and Clothing, The Hong Kong Polytechnic University, Hung Hom, Kowloon, Hong Kong, Tel 27666449 , Email tcshyam@polyu.edu.hk

Received: August 15, 2016 | Published: March 24, 2017

\section{Introduction}

In the recent decade, a growing number of companies in the fashion industry have adopted the ideology of "fast fashion". ${ }^{1}$ Fast fashion retailers produce highly fashionable products with production and distribution lead time shorter than traditional apparel retailers. Customer's expectations change due to current events and fast fashion enabled a close match of supply with the uncertain demand with the adoption of quick response policy. ${ }^{2}$ From the customers' perspectives, fast fashion retailers sell trendy items at affordable prices, hence gaining popularity in fashion industries and becoming a global fashion industry trend. ${ }^{3}$ There are different aspect that may affect the success of fast fashion, this paper focus on service quality expectation and cultural diversity.

\section{Fast fashion}

A fast fashion system basically included two essential elements: Firstly, the time lapse between production and distribution is short, resulting in a close match of supply and varying demand. ${ }^{4}$ Secondly, products are regarded as trendy and affordable universally. ${ }^{2}$ Fast fashion companies minimized costs in manufacturing, labor and logistic in order to offer a reasonable retail price to customers. For example, to lower the manufacturing cost, ZARA currently outsourced over $13 \%$ of the production process to China or Turkey where labor costs were much lower. ${ }^{5}$ As a result of offering low-price and high trendiness merchandise, customers were willing to refresh their wardrobes more frequently and tended to shop more, ${ }^{6}$ leading to the rising phenomenon of "disposable fashion". 7 Fast fashion customers wish to buy inexpensive clothes to follow the trend, and are willing to abandon their high quality standard. ${ }^{6}$ Therefore, fast fashion companies tend to produce products in an "acceptable" quality to lower the manufacturing cost ${ }^{8}$ in order to match with consumer' demand. In order to further reduce cost, most fast fashion retailers adopted self-service approach in service delivery, allowing customers to browse freely in the store instead of under the care of sales person. An Italian study on consumption practice of fast fashion consumers ${ }^{8}$ indicated that consumers appreciated the absence of pressure from salespersons during their shopping experience. On the other hand, an empirical study on Hong Kong fast fashion retailers' service delivery ${ }^{3}$ respondents commonly agreed that they do not expect any direct personal selling in fast fashion stores.

\section{Service quality}

There were four fundamental characteristics that have been regularly applied in describing services; these include intangibility, heterogeneity, inseparability and perishability. ${ }^{9}$ Intangibility was defined as not being palpable and an object. ${ }^{10}$ Intangibility is considered one of the most important characteristic of service and this characteristic of being intangible poses great effects on many aspects of service quality, such as higher uncertainty of the consumers' overall perception of services. ${ }^{11,12}$ Heterogeneity indicated service was unavailable to be standardized; hence variations occur because of human behavior and production uncertainties. Inseparability, which was firstly proposed by Say $\mathrm{JB}^{13}$ implied that service production and consumption usually take place at the same time. Perishability determined that service was unavailable to be stored and they would be ceased directly after the time of production. ${ }^{12}$

Service quality is defined as "a universal judgment or view related to the excellence of the service" To et al. ${ }^{14}$ It could be conceptualized as an overall assessment of service received by a consumer and viewed as the discrepancy between a consumer's perception and expectation in terms of degree and direction. ${ }^{15}$ Given the importance of service quality, researchers have developed method to measure service quality using SERVQUAL ${ }^{16}$ and RSQS ${ }^{17}$ methods. SERVQUAL, first developed by Parasuraman $\mathrm{A}^{16}$ is a widely adopted framework on measuring and evaluating service quality. ${ }^{16}$ Ten dimensions of service quality were suggested at first, they included Competence; 
Courtesy; Credibility; Security; Access; Communication; knowing the customer; Tangibles; Reliability; and Responsiveness. In 1991, the SERVQUAL was refined to include 5 dimensions, ${ }^{18}$ which includes Tangibles (Appearance of physical fixtures, surroundings, staff and the printed materials); Responsiveness (Willingness of service provider to provide immediate responds); Assurance (Ability and politeness of service providers to show certainty and trustworthiness to consumers); Reliability (Ability of how personnel are performing the promised service correctly); and Empathy (How the service provider is caring and gives individualized attention to the consumers, making them feeling valued). There are 22 items in the SERVQUAL measurement tool, 4 items evaluate the expectation and perception on Tangibles, 5 items evaluate Reliability, 4 items evaluate Responsiveness, 4 items evaluate Assurance and 4 items evaluate Empathy. Respondents score their agreement and disagreement on each of the 22 items in a sevenpoint Likert scale with "7" being excellent and " 1 " being Mediocre. Different research using the 22 items of the SERVQUAL has found the occurrence of different service dimensions in different setting. Did not find five-dimension structures of SERVQUAL in fashion retailing setting. Instead, four dimensions namely Personal Attention, Reliability, Tangibles and Convenience were emerged. ${ }^{19}$ Claim that SERVQUAL could not accurately capture the customers' perceptions of service quality universally in fashion retailing sector To WM, ${ }^{14}$ This may be because of different variation in customers' perception from different nationalities and cultures. ${ }^{20}$ In order to have a more focused scale, developed a Retail Service Quality Scale (RSQS) by qualitative investigation and reviewing SERVQUAL. ${ }^{17}$ RSQS has 5 dimensions including Physical aspects; Reliability; Personal interaction; Problem solving; and Policy. Physical Aspect included the visual appearance of physical facilities, such as racks and installations and the convenience of store layout design and the public area. Reliability is similar to the one SERVQUAL. Personal Interaction, related to politeness, helpfulness, confidence and trust of sales personnel in a retail store. It is somewhat related to responsiveness and assurance in SERVQUAL. Problem-solving, indicated the ability for the service provider to handle potential problems such as returns, complaints and dealing with consumers of different attitudes. Policy is related to different policies such as convenient parking, opening hours, variety of payment method and availability of an in-house credit store. RSQS consist of 28 items (17 items originated form SERQUAL0. Within the 28 items, 6 items address the dimension of Physical Aspect, 5 items address Reliability, 9 items address Personal Interaction, 3 items address Problem Solving while 5 items address the last dimension of Policy. Validation of RSQS performed in the Kazakhstan department store setting; indicated that the 5-dimensions structure of RSQS is accurate Das et al. ${ }^{21}$ However, another study in a Vietnam supermarket context, 4dimensions namely Service Personnel, Physical Aspects, Policy and Reliability emerged. ${ }^{22}$ Tested the validity of RSQS in Fashion retail chain stores in Malaysia, and the result suggested the 5 dimensions of RSQS were highly suitable for the measuring retail service quality in the Malaysian fashion retail setting. ${ }^{23}$ RSQS varied among different retail formats and national settings. Thus, customization and modification of the original 28 items are suggested to match cultural and environmental differences Furrer et al. ${ }^{24}$ Did not use three items of RSQS (contact with the store employees on phone; parking spaces for customers; and store offers its own credit card) when studying the service quality in a department chain store in Hong Kong as these items are not very relevant in Hong Kong Context. ${ }^{25}$

\section{Culture}

One of the adopted definitions of culture is "the collective programming of the mind which distinguishes the members of one group of people from those from other groups". ${ }^{26}$ From 1980 to 2001, Hofstede collected data from over 80,000 respondents from 66 different nationalities and 7 career fields $^{27}$ and found that the five dimensions that distinguish different cultures are power distance; uncertainty avoidance; individualism/collectivism; masculinity/ femininity; and long-term/short-term. The following table summarized the explanations of each dimension. Power distance is the extent of tolerance towards inequality among powerful groups and less powerful groups. ${ }^{27}$ Uncertainty Avoidance was the reaction of members in a group when facing ambiguities. Individualism referred to the bond among individual and the whole society. Masculinity/ Femininity was the male/female dominance in the society. Longterm/short-term was related to stability. Individuals valuing long-term orientation adored determination and endurance; while individuals valuing short-term Orientation adore stability. Hofstede cultural model is still widely used because of the numerical index it facilitates quantitative researches related to culture. ${ }^{24}$

According to Hong Kong 2011 Population Census Report (www. census2011.gov.hk), $94 \%$ of Hong Kong population is composed of Chinese (ethnically speaking Chinese), while 451,000 (6\%) of the population is composed of non-Chinese. Members of non-Chinese group are Indonesian $(133,377)$, Filipino $(133,018)$, White [mainly Caucasians] $(55,236)$, Indian $(28,616)$, Pakistani $(18,042)$, Nepalese $(16,518)$, Japanese $(12,580)$, Thai $(11,213)$, other Asian $(12,247)$ and others (30,336). According to Hong Kong Tourism Board (http:// partnernet.hktb.com/) for a country of about 7.5million, Hong Kong had 27million visitor arrivals from the first 6 month of 2016. In the month of June 2016 alone there were nearly 4.3 million visitors (mainland china 3.2M; Taiwan 176169; south and southeast Asia 319470; North Asia 179449; Australia, New Zealand \& South Pacific 55873; Europe, Africa \& the Middle East 137832; The Americas 133998).

\section{Cultural diversity and service quality}

According to existing researches exploring the 5-dimension structures of cultural diversity and service quality, interrelation between the two items were found. ${ }^{24}$ Collected data from university students of different cultural backgrounds, such as USA, international students in Singapore and Swiss. The study suggested customers in individualistic countries tended to have lower expectation in the dimension of assurance in service because they have more selfconfidence. In countries with high power distance, customers were deemed to have more power than the service provider in retail activities; they generally expected higher-quality service than customers in small power distance countries. Customers in strong uncertainty avoidance cultures expected service providers would be helpful in reducing uncertainty. This study adopted ${ }^{26}$ cultural model and SERVQUAL ${ }^{16}$ to measure service quality, the results supported that the service quality dimensions is significantly inter-related with Hofstede's cultural dimensions. ${ }^{28}$ Collected data from Hotel customers coming from USA, Germany, Japan and local Taiwan concluded cultural background was a determining predictor of service quality expectation. The study also pointed out customers from Western cultures generally rated higher in the service quality perception survey than that from Eastern cultures. ${ }^{29}$ Based in American dental health center also adopted Hofstede's cultural dimensions and SERVQUAL to explore the relationship between service quality perception and cultural diversity. The study validated the reliability of the two models and concluded that there were significant variation in service quality expectation among the Mexican-Americans and the Anglos. Malhotra 
et al. ${ }^{30}$ found that external environmental factors (standard of living; and economic development) were the most significant determinant factor influencing service quality expectation between developed and developing countries' customers.

\section{Research rationale}

Existing cross-cultural studies on customers' service quality expectations does not have consistent results. Cross-cultural researches focused in fast fashion retailing are limited. Studies on service quality are encouraged in various industries, as customers' expectation vary in different service industries. ${ }^{28}$ Given that fast fashion would continue to affect the fashion apparel industry in next decades, comprehensive research on service quality is needed to support its growth. The majority of studies related to fast fashion systems have focused on supply chain and operational management, ${ }^{4}$ while consumer-oriented studies in fast fashion are an under-explored academic field. ${ }^{6}$ Hong Kong is a multicultural city with tourism and retailing as core economic sectors. Multi-cultural research on service quality is useful and important for retailers when handling various multicultural customers.

\section{Methodology}

A pilot study using a small sample in order to reflect the targeted sample features was done in early January of 2016 before the largescale distribution of questionnaires. The main objective of the pilot test was to confirm the accuracy of use of languages (English, simplified Chinese characters, and complex Chinese characters). There were 15 participants involved in the pilot test, and they were all 15-35 aged frequent Hong Kong fast fashion shoppers. The participants included 4 Hong Kong-born permanent residents, 4 Mainland Chinese, 3 Nepalborn Hong Kong residents, 2 America-born Hong Kong residents and 2 Indonesia-born Hong Kong residents. They were all currently living in Hong Kong. They filled in the questionnaires with their own preference on language. Some adjustments on the questionnaire were done after the pilot test. Questions with subjective adjectives were amended to add explanations or more specific options in answers.

The final questionnaires were distributed online. The online questionnaire was generated with Google Form and distributed through popular social media platforms including Facebook and WeiBo. As Facebook is not widely used in China, the questionnaire was also distributed through WeiBo, a popular social media site in China, in order to reach more targeted respondents. The questionnaire was distributed for three-weeks within early to end of January in 2016.

\section{Participants}

The target respondents of this survey were fast fashion shoppers aged from 18 to 35 . They were expected to have shopping experience in fast fashion retailers in Hong Kong, regardless of their expenditure on these retailers. As this survey aimed to investigate the relationship between cultural diversity and service quality expectation, the target respondents were expected to be coming from different cultural backgrounds. Therefore, there wasn't any restriction on the nationalities of targeted respondents. But they were required to indicate their nationalities in terms of Hong Kong Chinese, Hong Kong non-Chinese, and Mainland Chinese and specified others. Basic demographic information including gender, nationality and income range was collected during the data collection process for additional analysis and reference.

\section{Questionnaire design}

The questionnaire consisted of four sections; they were namely, (a) Filtering Question, (b) Service Quality Expectation in Hong Kong Fast Fashion Retail Stores, (c) Cultural Dimensions and (d) Personal Information. In between sections, there were guidance notes to guide respondents in understanding and filling in the questionnaire accurately. There are 51 questions in total. The questionnaire was first designed as English and was then translated to Traditional Chinese and simplified Chinese. Thus, there were three versions in total for respondents to choose with their best language.

Section A-filtering questions: This section aimed to screen out respondents out of the sampling frame. Questions related to respondents' age and shopping experiences in fast fashion retailers, in order to ensure they were 18-35 aged and had shopped in Hong Kong fast fashion retailers before. This section included 3 questions.

Section B: service quality expectation in hong kong fast fashion retail stores: The development of the questionnaire on measuring respondents' service quality expectation was based of RSQS and was amended according to characteristics of Hong Kong fast fashion retail setting and the result of pilot test.

Three items were deleted. One related to Personal Interaction (Employees in this store should treat customers courteously on the telephone) and 2 related to policy (This store should provide plenty of convenient parking for customers; and this store should offer its own credit card).

One item in Physical Aspects was modified to eliminate subjective wordings and ensure equivalence in respondent's perceptions. Physical Aspects item 4 relating to public areas (The store should have convenient public areas) was modified to 2 items. Item 1 was "A fast fashion store should have convenient fitting rooms, and the acceptable queuing time should be: "1"-" 25 Minutes or above"; "2"-“"20-25 Minutes"; "3"-“15-20 Minutes"; "4”-“10-15 Minutes"; "5"-“6-10 Minutes"; “6”-“1-5 Minutes"; and "7"-"Immediate". Item 2 was "The store should have adequate counters of cashier, the acceptable queuing time for cashier should be:" with similar scale values as item 1. For 3 items additional examples added to better illustrate the meaning in a Kong context. For Physical Aspects of RSQS, item 1 "i.e. designed with recent ideas" was added. Similarly, for Physical Aspects of RSQS, item 3 "i.e. have positive impression on their appearance" were added. For Policy of RSQS, item 29 (Visa, MasterCard, American Express, JCB and China Union Pay) were added.

From the literature review, customers expected to be self- in any fast fashion retail stores, therefore, a new item was added to the original RSQS instrument. The item was added in the Personal interaction dimension. The item was "The staff are not expected to have direct selling to customers" and was on a 7 point Likert scale related to "1"-"Strongly Disagree" and "7"-."Strongly Agree". Apart from quality, fashionable design and affordable price were also important elements of fast fashion merchandise. Two new items was added to policy related to this. The items were "This store should offer fashionable merchandise" and "This store should offer affordable merchandise". Both were on a 7 point Likert scale related to "1"-"Strongly Disagree" and "7"-"Strongly Agree".

Section C and D: Section C aimed to access respondents' cultural 
dimensions, the level of upholding certain cultural values. The 15 items from ${ }^{27}$ were included in this section for accessing the 5 cultural dimensions namely Power Distance, Individualism, Uncertainty Avoidance, Masculinity and Long-term orientation. Section D focused on collecting data related to personal information such as respondents' gender, age, educational level, monthly income and place of birth

\section{Data analysis and results}

After the collection of data, the collected data were analyzed with an analytical tool, SPSS (ver. 22) developed by IBM. Statistical tests including descriptive statistics, reliability test, factor analysis, linear regression and correlation were applied to interpret the collected data for investigating the relationship between respondents' service quality expectation and cultural diversity.

\section{Simple statistics}

300 questionnaires were distributed online through social media platforms in three-week within early to end of January in 2016. 300 samples were received at the end of January in 2016; the response rate was $100 \% .9$ respondents were out of the targeted age range, 18 35 years old. 17 respondents had never shopped in Hong Kong fast Table I Descriptive statistics about Service Quality Expectation Dimensions fashion stores before. After filtering for our selection criteria, 283 valid samples were been used for the further analysis.

In this study, $63.96 \%$ of the respondents were female while $36.04 \%$ of the respondents were male. $69.61 \%$ of the respondents were in the age group of $18-24$ years old, $18.37 \%$ of the respondents were in the age group of 25-30 years old; and $12.01 \%$ of the respondents were in the age group of 31-35 years old group. Majority of respondents were with educational level of Undergraduate and Bachelor degree (88.71\%). Around half (51.59\%) of respondents had less than HKD $\$ 4,000$ monthly income. The second largest segment of monthly income was HKD $\$ 4,001-8,000$ which accounted for $35.69 \%$. Majority of respondents spend less than HKD\$500 or HKD\$5011,000 which accounted for $42.05 \%$ and $33.92 \%$ respectively. About half (51.94\%) of respondents were Hong Kong Chinese. While Hong Kong non-Chinese and Mainland Chinese accounted for $22.26 \%$ and $24.03 \%$ respectively. Nationalities other than Chinese included Indian, Indonesian, Nepalese and American. The descriptive statistics about Service Quality Expectation Dimensions are shown in Table 1. The descriptive statistics about cultural Orientation Dimensions are shown in Table 2.

\begin{tabular}{|c|c|c|}
\hline Items of service quality expectation & Mean & $\begin{array}{l}\text { Standard } \\
\text { deviation }\end{array}$ \\
\hline \multicolumn{3}{|l|}{ Physical Aspect (Items B I-B7) } \\
\hline $\mathrm{BI}: \mathrm{A}$ fast fashion store should have modern equipment and fixtures. & 5.06 & 1.84 \\
\hline B2:The physical facilities at a fast fashion store should be visually appealing. & 5.12 & 1.67 \\
\hline $\begin{array}{l}\text { B3: Materials associated with a fast fashion store's service (such as shopping bags, catalogs or statements) should } \\
\text { be visually appealing. }\end{array}$ & 5.01 & 1.68 \\
\hline B4:A fast fashion should have convenient fitting rooms, and the acceptable queuing time should be: & 5.06 & 1.84 \\
\hline B5:The store should have adequate counters of cashier, the acceptable queuing time for cashier should be: & 5.11 & 1.66 \\
\hline B6:The store layout at the store should make it easy for customers to find what they need. & 5.01 & 1.69 \\
\hline B7:The store layout of the store should make it easy for customers to move around in the store. & 5.37 & 2.21 \\
\hline \multicolumn{3}{|l|}{ Reliability (Items B8-B I I) } \\
\hline B8:When the store promises to do something by a certain time, it should do so. & 4.89 & 1.77 \\
\hline B9:The store should perform the service right at the first time & 4.6 & 1.6 \\
\hline BI0:The store should have merchandise available when the customers want it. & 4.64 & 1.8 \\
\hline BII:The store should provide error-free sales transactions and records. & 4.98 & 1.51 \\
\hline \multicolumn{3}{|l|}{ Personal Interaction (Items B I 2-B20) } \\
\hline BI2:The staff should have the knowledge to answer customers' questions. & 5.6 & 1.73 \\
\hline BI3:The behavior of staff should show confidence to customers. & 5.33 & 1.84 \\
\hline BI4: Customers should feel safe in their transactions with this store. & 5.39 & 1.66 \\
\hline BI5:The staff should be immediate available to serve customers. & 4.6 & 1.6 \\
\hline B16:The staff should tell the customers exactly when services would be performed. & 4.64 & 1.8 \\
\hline BI7:The staff should never be too busy to respond to customers' requests. & 4.98 & 1.51 \\
\hline BI8:The staff should give customer individual attention. & 5.45 & 1.65 \\
\hline B19:The staff should be consistently polite with customers. & 5.74 & 1.38 \\
\hline B20:The staff are not expected to have direct selling to customers. & 5.56 & 1.54 \\
\hline \multicolumn{3}{|l|}{ Problem Solving (Item B2 I-B23) } \\
\hline B21:The store should be willing to handle returns and exchanges. & 5.3 & 1.79 \\
\hline
\end{tabular}


Table Continued.

\begin{tabular}{|c|c|c|}
\hline Items of service quality expectation & Mean & $\begin{array}{l}\text { Standard } \\
\text { deviation }\end{array}$ \\
\hline B22:When a customer has a problem, the staff should show a sincere interest in solving it. & 5.16 & 1.58 \\
\hline B23:The staff should be able to handle customer complaints directly and immediately. & 5.14 & I.78 \\
\hline \multicolumn{3}{|l|}{ Policy (B24-B28) } \\
\hline B24:The store should offer high quality merchandise. & 5.35 & 1.7 \\
\hline B25:The store should offer fashionable merchandise. & 5.45 & 1.65 \\
\hline B26:The store should offer affordable merchandise. & 5.74 & 1.38 \\
\hline B27:The store's operating hours should be convenient for all of the customers. & 5.41 & 1.68 \\
\hline B28:This store should accept most major credit cards. & 5.56 & 1.54 \\
\hline
\end{tabular}

Table 2 Descriptive statistics about Cultural Orientation Dimensions

\begin{tabular}{|c|c|c|}
\hline Items of cultural orientation & Mean & $\begin{array}{l}\text { Standard } \\
\text { deviation }\end{array}$ \\
\hline \multicolumn{3}{|l|}{ Power Distance (Item CI-C3) } \\
\hline $\mathrm{Cl}$ : One of my main goals in life has been to make my parents proud of. & 4.84 & 1.81 \\
\hline C2: One should always follow a superior's instructions. & 4.56 & 1.61 \\
\hline C3: Regardless of their qualities and fault, one must always respect their parents. & 4.46 & 1.68 \\
\hline \multicolumn{3}{|l|}{ Individualism (Items C4-C6) } \\
\hline C4: I want to have sufficient time for my personal or family life. & 5.06 & 1.84 \\
\hline C5: I want to have an element of adventure and variety in my life. & 5.12 & 1.67 \\
\hline C6: I will not buy things at $20 \%$ higher than usual price if it would help protecting the environment. & 5.01 & 1.68 \\
\hline \multicolumn{3}{|l|}{ Uncertainty Avoidance (Items C7-C9) } \\
\hline C7: Rules should not be broken, even if it is for my own benefit. & 5.59 & 1.76 \\
\hline C8:We should emphasize tradition more than high technology. & 5.33 & 1.84 \\
\hline C9. I often feel nervous or tense. & 5.39 & 1.66 \\
\hline \multicolumn{3}{|l|}{ Masculinity (CIO-CI2) } \\
\hline CI0: Both, men and women should contribute to household income. & 4.48 & 2.11 \\
\hline $\mathrm{CII}$ : Cooperation is the key to advancement in life. & 4.58 & 1.35 \\
\hline $\mathrm{CI}$ 2: Generally speaking, most people can be trusted. & 4.66 & 1.79 \\
\hline \multicolumn{3}{|l|}{ Long-term Orientation (CI3-CI5) } \\
\hline $\mathrm{CI}$ 3: In my private life, a good paid job is extremely important. & 4.92 & 1.69 \\
\hline $\mathrm{Cl} 4$ : In my private life, saving money is extremely important. & 5.01 & 1.67 \\
\hline CI5: In my private life, "Stability" is an extremely important value. & 4.71 & 1.98 \\
\hline
\end{tabular}

\section{Reliability test}

Reliability test (Cronbach's Alpha) was applied to the data set to confirm the reliability for further analysis. Cronbach's Alpha for Physical Aspect items was 0.890. Cronbach's Alpha for Reliability items was 0.722. Cronbach's Alpha for Personal Interaction items was 0.875. Cronbach's Alpha for Problem Solving items was 0.820 . Cronbach's Alpha for Policy items was 0.790 . For cultural Orientation Dimensions, Cronbach's Alpha for Power Distance was 0.786. Cronbach's Alpha for Individualism was 0.887. Cronbach's Alpha for Uncertainty Avoidance was 0.900 . Cronbach's Alpha for Masculinity was 0.821 . Cronbach's Alpha for Long-term Orientation was 0.888 . All the Cronbach's Alphas are greater than 0.7 indicating consistency between the items.

\section{Factor analysis for the service quality expectation} dimensions

Factor analysis for the Service Quality Expectation Dimensions was carried out. Factor analysis of the Physical Aspect items indicated that 2 factors has Eigen values $>1$ and can explain $80.2 \%$ of variance. Factor 1 (explaining $60.4 \%$ of variance) was loaded on B1, B2, B3 and B7 somewhat representing tangible physical aspects, hence it was named "Physical aspects". Factor 2 (explaining 19.8\% of variance) was loaded on B4, B5, and B6 somewhat representing convenience, hence it was named "Convenience". Factor analysis of the Reliability items indicated that 1 factor has Eigen values $>1$ and can explain $60.2 \%$ of variance. Factor analysis of the Personal Interaction items indicated that 2 factors has Eigen values $>1$ and can explain $63.8 \%$ 
of variance. Factor 1 (explaining $50.8 \%$ of variance) was loaded on B12, B14, B15, B16, and B17 somewhat representing knowledge and confidence aspects of Personal Interaction was named "Knowledge", while factor 2 (explaining $13.1 \%$ of variance) was loaded on B13, B18, B19 and B20 somewhat representing behavioral aspects of Personal Interaction was named "Attitude". Factor analysis of the problem solving items indicated that 1 factor has Eigen values $>1$ and can explain $73.6 \%$ of variance. Factor analysis of the Policy items indicated that 1 factor has Eigen values $>1$ and can explain $56.4 \%$ of variance. In order to explain more than $60 \%$ of variance, 2 factor analysis was done. Factor 1 (explaining 56.4\% of variance) was loaded on B24, B25, and B26 somewhat representing Policy toward products and the factor was named "product policy", while factor 2 (explaining $18.7 \%$ of variance) was loaded on B27, and B28 somewhat representing Policies towards services was named "service policy". The mean for the different factors are shown in Table 3.

Table 3 Customers' Service Quality Expectations towards Hong Kong fast fashion store

\begin{tabular}{ll}
\hline Service quality expectation & Mean \\
\hline Physical aspect & 5.14 \\
Convenience & 5.06 \\
Reliability & 4.78 \\
Knowledge & 5.04 \\
Attitude & 5.52 \\
Problem solving & 5.2 \\
Product policy & 5.58 \\
Service policy & 5.34 \\
\hline
\end{tabular}

\section{Factor analysis for cultural dimensions}

Factor analysis for the Cultural dimensions was carried out. Factor analysis of the Power distance items indicated that 1 factor has Eigen values $>1$ and can explain $70.3 \%$ of variance. Factor analysis of the Individualism items indicated that 1 factor has Eigen values $>1$ and can explain $81.7 \%$ of variance. Factor analysis of the Uncertainty Avoidance items indicated that 1 factor has Eigen values $>1$ and can explain $83.5 \%$ of variance. Factor analysis of the Masculinity items indicated that 1 factor has Eigen values $>1$ and can explain $74.3 \%$ of variance. Factor analysis of the Long-term Orientation items indicated that 1 factor has Eigen values $>1$ and can explain $82.1 \%$ of variance.

\section{Relationship between cultural dimensions and service quality expectations}

Strong regression between service quality dimensions and cultural dimensions are shown in Figure 1. The power distance and masculinity dimensions of culture did not seem to have any relationship with service quality expectations, while uncertainty avoidance; Individualism and long term orientation seems to have a relationship.

When studying the linear relationship between Cultural dimensions and Service Quality Expectations, service quality expectation is the dependent variable while cultural orientation is the independent variable. Step-wise linear Regression was used to find relationship between Physical Aspect, Reliability, Personal Interaction, Problem Solving and Policy as dependent variables and Power Distance (PD), Individualism (I), Uncertainty Avoidance (UA), Masculinity (M), and Long-term Orientation (LO) as independent variables. The results are as follows:

\begin{tabular}{|l|l|}
\hline Physical aspect $=-0.452+0.302 \mathrm{UA}+0.725 \mathrm{I}+0.057 \mathrm{LO}$ & $\mathrm{R}^{2}=0.982$ \\
\hline Convenience $=2.264+0.5 \mathrm{I} 4 \mathrm{UA}$ & $\mathrm{R}^{2}=0.278$ \\
\hline Reliability $=1.636+0.412 \mathrm{UA}+0.184 \mathrm{LO}$ & $\mathrm{R}^{2}=0.488$ \\
\hline Knowledge $=1.220+0.548 \mathrm{UA}+0.167 \mathrm{I}$ & $\mathrm{R}^{2}=0.755$ \\
\hline Attitude $=2.177+0.615 \mathrm{UA}$ & $\mathrm{R}^{2}=0.585$ \\
\hline Problem solving $=1.695+0.645 \mathrm{UA}$ & $\mathrm{R}^{2}=0.493$ \\
\hline Product policy $=2.994+0.476 \mathrm{UA}$ & $\mathrm{R}^{2}=0.368$ \\
\hline Service policy $=3.139+0.412 \mathrm{UA}$ & $\mathrm{R}^{2}=0.214$ \\
\hline
\end{tabular}

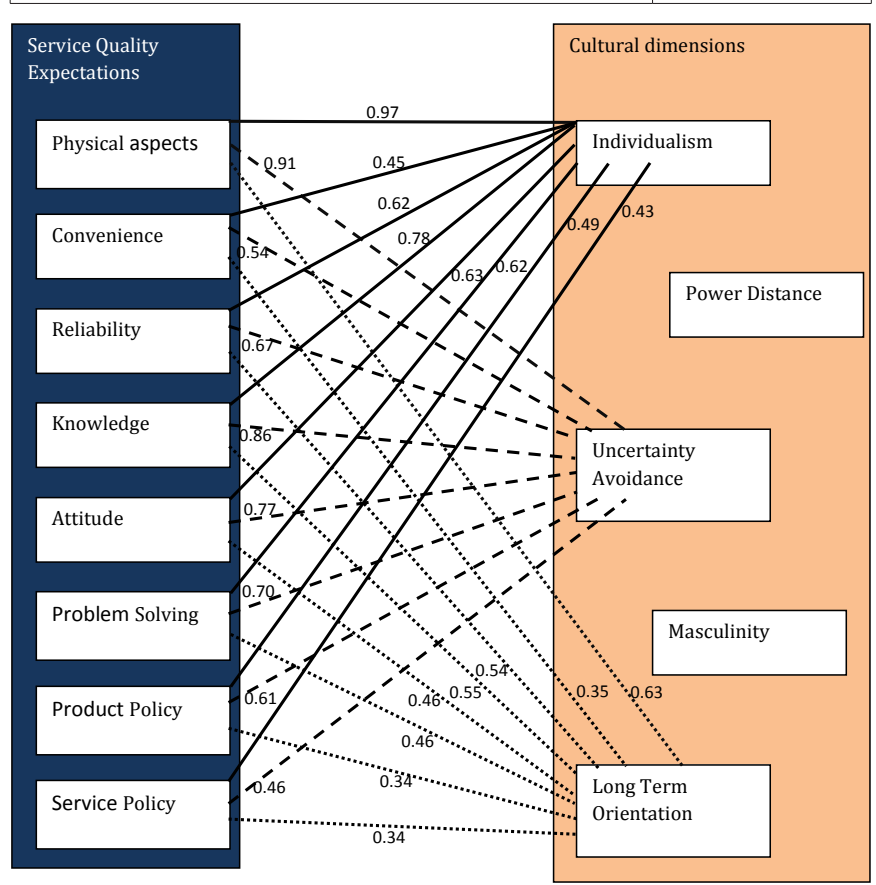

Figure I Relationship between service quality and Cultural dimensions (values are $\mathrm{R}^{2}$ correlation values).

\section{Discussion and conclusion}

In this study, modified RSQS was applied to measure customers' service quality expectation after validation. Five dimensions of service quality were suggested in RSQS ${ }^{17}$ namely Physical Aspect, Reliability, Personal Interaction, Problem Solving and Policy. RSQS was developed for general retail settings, while the setting was specifically in Hong Kong fast fashion retailing in this study. Cronbach Alpha reliability tests to review the internal consistency and was proved to be reliable for further analysis (with all Cronbach Alpha over 0.7). Based on factor analysis we obtained 8 dimensions of Service Quality Expectation namely Physical aspect; Convenience; Reliability; Knowledge; Attitude; Problem solving; Product policy and Service policy. The cultural dimensions were same as previous research which was power distance, individualism, uncertainty avoidance, masculinity and long term orientation. There were relationship between service quality expectation and cultural dimensions. The power distance and masculinity dimensions of culture did not seem to have any relationship with service quality expectations, while uncertainty avoidance; Individualism and long term orientation seems to have a relationship. Regression equations between the 8 dimensions of Service Quality Expectation and cultural dimensions were also 
developed. All the dimensions of Service Quality Expectation are influenced by uncertainty avoidance. The findings from this study will be useful for global fast fashion retailers planning to expand to Hong Kong market. Further research and additional analysis may be needed to further understand the relationship between service quality expectation in fast fashion and the cultural dimensions.

\section{Acknowledgments}

None.

\section{Conflict of interest}

Author declares there is no conflict of interest in publishing the article.

\section{References}

1. Passariello C. Logistics are in vogue with designers-As slump threatens luxury goods, systems to track consumer tastes and tweak offerings win converts. Wall Street Journal. USA; 2008.

2. Cachon GP, Swinney R. The value of fast fashion: Quick response, enhanced design, and strategic consumer behavior. Management Science. 2011;57(4):778-795.

3. Choi TM. Fast fashion systems: Theories and applications. CRC Press, USA; 2013. p. 158.

4. Bruce M, Daly L. Buyer behavior for fast fashion. J Fashion Market \& Management: An International J. 2006;10(3):329-344.

5. Tokatli N. Global sourcing: insights from the global clothing industry-the case of Zara, a fast fashion retailer. J Economic Geography. 2008;8(1):21-38.

6. Bhardwaj V, Fairhurst A. Fast fashion: response to changes in the fashion industry. The International Review of Retail, Distribution and Consumer Research. 2010;20(1):165-173.

7. Fletcher K. Sustainable fashion and textiles: design journeys. 2nd ed. Routledge, UK; 2014. p. 288.

8. Gabrielli V, Baghi I, Codeluppi V. Consumption practices of fast fashion products: a consumer-based approach. J Fashion Market \& Management: An International J. 2013;17(2):206-224.

9. Moeller S. Characteristics of services-a new approach uncovers their value. J Services Market. 2010;24(5):359-368.

10. Lovelock C, Gummesson E. Whither services marketing? In search of a new paradigm and fresh perspectives. J Service Res. 2004;7(1):20-41.

11. McDougall GH, Levesque T. Customer satisfaction with services: putting perceived value into the equation. JServices market. 2000;14(5):392-410.

12. Vargo SL, Lusch RF. The four service marketing myths remnants of a goods-based, manufacturing model. J Service res. 2004;6(4):324-335.

13. Say JB. A Treatise on Political Economy. August M Kelley, New York, USA; 1836. p. 492.
14. To WM, Tam JF, Cheung MF. Explore how Chinese consumers evaluate retail service quality and satisfaction. Service Business. 2013;7(1):121-142.

15. Shahin A, Samea M. Developing the models of service quality gaps: a critical discussion. Business Management \& Strategy. 2010;1(1):E2.

16. Parasuraman A, Zeithaml V, Berry L. SERVQUAL: a multiple-item scale for measuring consumer perceptions of service quality. $J$ Retailing. 1988;64(1):12-40.

17. Dabholkar PA, Thorpe DI, Rentz JO. A measure of service quality for retail stores: scale development and validation. $J$ the Academy of Market Sci. 1995;24(1):3-16.

18. Gaur SS, Agrawal R. Service quality measurement in retail store context: a review of advances made using SERVQUAL and RSQS. The Marketing Review. 2006;6(4):317-330.

19. Bishop Gagliano K, Hathcote J. Customer expectations and perceptions of service quality in retail apparel specialty stores. J Services Market. 1994;8(1):60-69.

20. Kim S, Jin B. Validating the retail service quality scale for US and Korean customers of discount stores: an exploratory study. J Services Market. 2002;16(3):223-237.

21. Das A, Kumar V, Saha GC. Retail service quality in context of CIS countries. International $J$ Quality \& Reliability Management. 2010;27(6):658-683.

22. Nguyen DDN, Le Nguyen H. Determinants of retail service quality: A study of supermarkets in Vietnam. Sci \& Technol Development. 2007;10(8):15-23.

23. Yeap Ai Leen J, Ramayah T. Validation of the RSQS in apparel specialty stores. Measuring Business Excellence. 2011;15(3):16-18.

24. Furrer O, Liu BSC, Sudharshan D. The relationships between culture and service quality perceptions basis for cross-cultural market segmentation and resource allocation. J Service Res. 2000;2(4):355-371.

25. Siu NY, Tak Hing Cheung J. A measure of retail service quality. Marketing Intelligence \& Planning. 2001;19(2):88-96.

26. Hofstede G. The business of international business is culture. International business review. 1994;3(1):1-14.

27. Hofstede G. Culture's consequences: Comparing values, behaviors, institutions and organizations across nations. 2nd ed. Sage, USA; 2001.

28. Shih CH. Effects of culture on service quality and customer satisfaction ratings. Unpublished $\mathrm{PhD}$ Thesis. 2006.

29. Ueltschy LC, Krampf RF. Cultural sensitivity to satisfaction and service quality measures. J Market Theory \& Practice. 2001;9(3):14-31.

30. Malhotra NK, Ulgado FM, Agarwal J, et al. International services marketing: a comparative evaluation of the dimensions of service quality between developed and developing countries. International Marketing Review. 1994;11(2):5-15. 